\title{
The Influence of Organizational Support on Career Commitment of New Generation Employees
}

\author{
Fang Jiarui * \\ International Business School, Shaanxi Normal University, Xi'an, Shaanxi 710119, China \\ *Corresponding author. Email:2412625862@qq.com
}

\begin{abstract}
With the gradual entry into the post-90s, the new generation of employees has gradually become the main group in the job market, and the post-90s employees are no longer a fresh vocabulary; However, the new characteristics of the new generation of employees are that they make organizations or enterprises unprepared, especially the high turnover rate of employees after the 1990s, which makes the research on the new generation of employees become a hot issue Among them, the research on career commitments of the new generation of employees is rare, so this article will use this as the entry point. To explore the impact of organizational support on the career commitment of the new generation of employees. This paper studies the new generation of employees as the object, constructs a theoretical model of the impact of organizational support on career commitments, and conducts empirical research on the method of sending questionnaires to 205 new generation employees. The research results show that the sense of organizational support has a significant positive impact on the career commitment of the new generation of employees. Among them, in the three dimensions of organizational support, interest in care is most significant for the emotional commitment in the career commitment of the new generation of employees. Positive effect. Gender and age have no significant effect on the sense of organizational support and career commitment for new generation employees. These conclusions have reference value for the management practice of the company.
\end{abstract}

Keywords: New generation employees, Sense of organizational support, Professional commitment

\section{Introduction}

The new generation of employees refers to workers born after the 1980s and 1990s and taking responsibilities in various enterprises. According to statistics, there are 7.95 million college graduates in 2017, and 8.2 million in 2018 . In 2019 , the number of college graduates nationwide hit 8.34 million. The data shows that the new generation of employees has become a force that cannot be ignored, with a greater proportion of them serving as the backbone of enterprises and value creators. However, their distinctive characteristics have brought unprecedented challenges to the human resources management of enterprises. Conflicts between the existing management system and the new generation of employees have become an important issue for researchers to study.

Career commitment is an important topic in occupational psychology both at home and abroad in the past 20 years. Career commitment refers to the recognition and devotion of employees to the occupation they are engaged in. Previous studies have shown that employees with high career commitment will show recognition of the occupation they are engaged in and thus invest more in their professional activities and are reluctant to change the occupation they are currently engaged in. On the contrary, employees with low career commitment are bored with the current occupation, unwilling to take their work seriously, or even reluctant to finish their duties. The new generation of employees are more prone to low work efficiency caused by low career commitment. Therefore, it is of vital importance for managers to improve the career commitment of the new generation of employees, making it a hot topic for researchers.

Perceived organizational support has always been an important antecedent variable of career commitment. Perceived organizational support refers to employees' perception of the organization in the following aspects: how much the organization values his/her contribution, and how much the organization values the welfare and interests of its employees. Previous studies have shown that Perceived Organizational Support has a great impact on employees' behavior and attitude. Employees with a higher level of perceived organizational support are characterized by better performance and lower turnover intention. The new generation of employees who grow up with the development of Internet has a greater need for perceived organizational support than their older counterparts. A higher level of perceived organizational support enables employees to be more engaged in their work, thus enjoying their career with more career commitment.

There have been few studies on career commitment from the perspective of perceived organizational support among existing studies on the new generation of employees. The new generation of employees don't think of themselves as accessories of the organization. Instead, they prefer to use 
partners to describe their relationship with the organization. Therefore, both enterprises and organizations need to change their ideology and regard employees as a part of the organization or as a partner. Based on the theories concerning social exchange, perceived organizational support and career commitment, this paper takes the new generation of employees as the subject to investigate the influence of perceived organizational support on career commitment among the new generation of employees from various dimensions. Based on results of the study, this paper provides suggestions for human resources management strategies of organizations and system construction so that the new generation of employees can give a full play to their talents.

\section{Theoretical Review and Assumptions}

\subsection{Theoretical Review}

Perceived Organizational Support was first proposed by American psychologist Eisenberger, which is a variable used to describe the overall perception of how much the organization values employees' contributions and concern for employees' well-being [1]. McMillin supplemented Eisenberger's view through his own research. McMillin believed that a positive perception of organizational support from employee came from not only sharing and caring about employees' happiness, but also from instrumental organizational support to employees, which was equally important [2]. Ling Wenquan divided perceived organizational support into three dimensions: employees' perception of organizational support, caring about employees' interests and recognition of their values [3].

Occupational commitment, or career commitment is a new term that has arisen only in the past 20 years, which refers to a psychological connection between a person and the occupation he is engaged in, that is, how much the person is likely to stick to the current career caused by personal recognition and emotional dependence on the occupation he is engaged in, the devotion to the occupation as well as internalized social norms. It's a variable subject to the employee's attitude to the occupation, the promise of the individual to bear certain professional responsibilities, and the "mental contract" signed by the individual to prove his commitment to the occupation. In Lee's multivariate analysis of career commitment, career commitment refers to a psychological bond established between individual and career [4]. Laurel and Parbudyal believed that occupational commitment can be measured not only personal recognition of the value of one's job, but also by the amount of time he spends in the occupation for further improvement [5]. Becker and Hornhauser believed that career commitment represents employees' desire to participate in activities related to their occupation [6].

\subsection{Perceived Organizational Support and Career Commitment}

Based on the theory of social exchange and the principle of reciprocity, employees are likely to have a strong recognition of the organization and sense of responsibility to take care of the organization when they are given sufficient support from the organization. One of the ways for employees to care for the enterprise is to keep participating in the occupation with more devotion and greater passion for the work, thus raising their level of career commitment. Previous studies have suggested that perceived organizational support has a significant positive effect on career commitment [7]. The same conclusion has been reached in the study of university staff: the more the perceived organizational support, the higher level of career commitment among the staff [8]. Similarly, studies on knowledge-based workers have found that the perceived organizational support among employees has a significant positive impact on the three dimensions of career commitment, which were ranked from high to low as affective commitment, normative commitment, and continuance commitment [9].

Based on the analysis above, the perceived organizational support can well explain changes of career commitment. In other words, the higher the perceived organizational support, the higher the career commitment. Moreover, perceived organizational support has a significant impact on all dimensions of career commitment. However, few studies have taken the new generation of employees as the subject for research. The new generation of employees are born in a different environment from older employees, thus creating obvious differences between the two in recognition of identity and self-value. It is unknown if the perceived organizational support would affect the career commitment of the new generation of employees. This paper investigated the new generation of employees and proposed the following assumptions:

H1a Work support has a significant positive impact on affective commitment

H1b Work support has a significant positive impact on continuance commitment

H1c Work support has a significant positive impact on normative commitment

H1d Value recognition has a significant positive impact on affective commitment

H1e Value recognition has a significant positive impact on continuance commitment

H1f Value recognition has a significant positive impact on normative commitment

$\mathrm{H} 1 \mathrm{j}$ Caring about the interests of employees has a significant positive impact on affective commitment H1h Caring about the interests of employees has a significant positive impact on continuance commitment H1i Caring about the interests of employees has a significant positive impact on normative commitment 


\section{Research Methods}

\subsection{Design of Questionnaire}

This questionnaire mainly consists of questions concerning basic information, employees' perceived organizational support, and career commitment. The questionnaire on perceived organizational support and career commitment is scored using Likert scale, with 5 points being very consistent and 1 point being very inconsistent. The higher the score given by the new generation of employees, the more satisfied he/she is with the evaluated dimensions.

The Organizational Support Questionnaire (OSQ) has 26 questions covering the three dimensions proposed by $\mathrm{Yi}$ Shizhi (2013), including work support, value recognition and caring about employees' interests [10]. The $\alpha$ value of this scale is 0.946 .

The questionnaire of career commitment is based on the scale developed by Meyer and Allen (1993) to measure the career commitment of the new generation of employees. The scale includes three dimensions, namely affective commitment, continuance commitment and normative commitment, with a total of 21 questions [11]. The $\alpha$ of the scale is 0.931 , with good reliability.

\subsection{Statistical Analysis}

\subsubsection{Description and Relevance}

In Table 1, the significance of work support, affective commitment, continuance commitment and normative commitment is less than 0.01 , with correlation coefficients of $0.596,0.486$ and 0.531 respectively, all of which are greater than 0 . Therefore, there is a significant positive correlation between work support and affective commitment, continuance commitment and normative commitment. At the same time, the significance of value recognition and affective commitment, discipline commitment and normative commitment stay at 0.000 less than 0.01 , with correlation coefficients of $0.641,0.476$ and 0.431 respectively, all of which are greater than 0 . Value recognition and affective commitment, continuance commitment and normative commitment all show significant positive correlation. It is also found that the significance of caring for employees' interests and affective commitment, continuance commitment and normative commitment is less than 0.01 , with correlation coefficients of $0.757,0.518$ and 0.501 respectively, all of which are greater than 0 . Therefore, caring for employees' interests and affective commitment, continuance commitment and normative commitment all present significant positive correlation. This paper will make further regression analysis of the nine assumptions above.

Table 1 Correlation analysis results

\begin{tabular}{|c|c|c|c|c|c|c|c|c|}
\hline & Mean & variance & $\begin{array}{c}\text { Work } \\
\text { support }\end{array}$ & $\begin{array}{c}\text { Value } \\
\text { recognition }\end{array}$ & $\begin{array}{c}\text { Caring } \\
\text { interests }\end{array}$ & $\begin{array}{c}\text { affective } \\
\text { commitment }\end{array}$ & $\begin{array}{c}\text { continuance } \\
\text { commitment }\end{array}$ & $\begin{array}{c}\text { normative } \\
\text { commitment }\end{array}$ \\
\hline $\begin{array}{c}\text { Work } \\
\text { support }\end{array}$ & 3.96 & 0.371 & 1 & $.728^{* *}$ & $.661^{* *}$ & $.596^{* *}$ & $.486^{* *}$ & $.531^{* *}$ \\
\hline $\begin{array}{c}\text { Value } \\
\text { recognition }\end{array}$ & 3.96 & 0.498 & $.728^{* *}$ & 1 & $.754^{* *}$ & $.641^{* *}$ & $.476^{* *}$ & $.431^{* *}$ \\
\hline $\begin{array}{c}\text { Caring } \\
\text { interests }\end{array}$ & 3.99 & 0.527 & $.661^{* *}$ & $.754^{* *}$ & 1 & $.757^{* *}$ & $.518^{* *}$ & $.501^{* *}$ \\
\hline $\begin{array}{c}\text { affective } \\
\text { commitment }\end{array}$ & 3.99 & 0.456 & $.596^{* *}$ & $.641^{* *}$ & $.757^{* *}$ & 1 & $.736^{* *}$ & $.712^{* *}$ \\
\hline $\begin{array}{l}\text { continuance } \\
\text { commitment }\end{array}$ & 4.01 & 0.538 & $.486^{* *}$ & $.476^{* *}$ & $.518^{* *}$ & $.736^{* *}$ & 1 & $.719^{* *}$ \\
\hline $\begin{array}{l}\text { normative } \\
\text { commitment }\end{array}$ & 4.07 & \multicolumn{7}{|l|}{0.481} \\
\hline
\end{tabular}

\subsubsection{Regression Analysis}

From the analysis above, it is observed that for the new generation of employees, higher perceived organizational support will be rewarded by a stronger career commitment from the employees. The paper will carry out regression analysis of perceived organizational support to verify the three dimensions of career commitment, namely affective commitment, continuance commitment, and normative commitment and determine whether there is a causal relationship between the three and what impact they have on each other. This study uses SPSS 19.0 to analyze relevant variables to find out the specific relationship between dependent variables and independent variables. The results of the regression analysis are shown in Table 2 below, where the work support, value recognition and caring about employees' interests were used as independent variables and affective commitment as 
dependent variable. Based on the results, we conclude that the $\mathrm{F}$ test is of significance with an adjusted $\mathrm{R}^{2}$ of 0.77 , indicating that the three variables of work support, value recognition and caring about employees' interests can explain $77 \%$ of the variance of affective commitment. The coefficient of work support is $0.149,0.186$ for value recognition, and 0.558 for the variable of caring about employees' interests. Therefore, the regression equation is given by:

Affective commitment $=0.725+0.149 *$ work support + $0.186 *$ value recognition $+0.558 *$ caring about employees' interests

Table 2 Regression Analysis of Affective Commitment Based on Work Support, Value Recognition and Caring about Employees' Interests

\begin{tabular}{|c|c|c|c|c|c|c|c|c|}
\hline & \multirow[t]{2}{*}{ model } & \multicolumn{2}{|c|}{$\begin{array}{l}\text { Unstandardized } \\
\text { coefficient }\end{array}$} & \multirow[t]{3}{*}{$\begin{array}{c}\text { Standard } \\
\text { coefficient }\end{array}$} & \multirow[t]{2}{*}{$\mathrm{t}$} & \multirow[t]{2}{*}{ Sig. } & \multirow[t]{2}{*}{$\mathrm{R}^{2}$} & \multirow[t]{2}{*}{ adjusted $R^{2}$} \\
\hline & & $\mathrm{B}$ & $\mathrm{SE}$ & & & & & \\
\hline \multirow{4}{*}{1} & $\mathrm{~b}$ & .725 & .205 & & 3.544 & 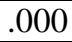 & \multirow{4}{*}{.770} & \multirow{4}{*}{.592} \\
\hline & Work support & .149 & .075 & .134 & 1.981 & .000 & & \\
\hline & $\begin{array}{c}\text { Value } \\
\text { recognition }\end{array}$ & .186 & .074 & .090 & 1.166 & .000 & & \\
\hline & $\begin{array}{l}\text { Caring } \\
\text { interests }\end{array}$ & .558 & .066 & .600 & 8.481 & .000 & & \\
\hline
\end{tabular}

Based on the analysis above, work support, value recognition and caring about employees' interests have significant positive effects on affective commitment, thus confirming assumptions of $\mathrm{H} 1 \mathrm{a}, \mathrm{H} 1 \mathrm{~d}$ and $\mathrm{H} 1 \mathrm{j}$.

The results of regression analysis using spss19.0 are shown in Table 3 below, where work support, value recognition and caring about employees' interests are taken as independent variables and continuance commitment as dependent variable. Based on the results, we conclude that the $\mathrm{F}$ test is of significance with an adjusted $\mathrm{R}^{2}$ of 0.307 , indicating that work support, value recognition and caring about employees' interests can explain $30.7 \%$ of the variance of continuance commitment, where the coefficient of work support is $0.268,0.184$ for value recognition, and 0.313 for caring about employees' interests. Therefore, the regression equation is given by: Continuance commitment $=1.266+0.268^{*}$ work support+0.184*value recognition $+0.313 *$ caring about employees' interests

Based on the analysis above, work support, value recognition and caring about employees' interests have significant positive effects on affective commitment, thus confirming the assumptions of H1b, H1e and H1h.

The results of regression analysis are shown in Table 4 below, where work support, value recognition and caring about employees' interests are taken as independent variables and normative commitment as dependent variable. Based on the results, we conclude that the F test is of significance with an adjusted $\mathrm{R}^{2}$ of 0.325 , indicating that work support, value recognition and caring about employees' interests can explain $32.5 \%$ of the variance of normative commitment, where the coefficient of work support is $0.443,0.283$ for value recognition, and 0.294 for caring about employees' interests. Therefore, the regression equation is given by:

Normative commitment $=1.306+0.443 *$ work support $+0.283 *$ value recognition $+0.294 *$ caring about employees' interests

Based on the analysis above, work support, value recognition and caring about employees' interests have significant positive effects on normative commitment, thus confirming the assumptions of H1c, H1f and H1i.

Based on the analysis above, all 9 assumptions are verified in this paper.

Table 3 Regression Analysis of Continuance Commitment Based on Work Support, Value Recognition and Caring about Employees' Interests

\begin{tabular}{|c|c|c|c|c|c|c|c|c|}
\hline \multirow{2}{*}{\multicolumn{2}{|c|}{ model }} & \multicolumn{2}{|c|}{ Unstandardized coefficient } & Standard coefficient & \multirow{2}{*}{$\mathrm{t}$} & \multirow{2}{*}{ Sig. } & \multirow{2}{*}{$\mathrm{R}^{2}$} & \multirow{2}{*}{ adjusted $R^{2}$} \\
\hline & & B & SE & & & & & \\
\hline \multirow{4}{*}{2} & $\mathrm{~b}$ & 1.266 & .290 & & 4.366 & .000 & \multirow{4}{*}{.554} & \multirow{4}{*}{.307} \\
\hline & Work support & .268 & .106 & .223 & 2.518 & .000 & & \\
\hline & Value recognition & .184 & .105 & .081 & .801 & .000 & & \\
\hline & Caring interests & .313 & .093 & .310 & 3.357 & .000 & & \\
\hline
\end{tabular}

a. Dependent variable: continuance commitment 
Table 4 Regression Analysis of Continuance Commitment Based on Work Support, Value Recognition and Caring about Employees' Interests

\begin{tabular}{|c|c|c|c|c|c|c|c|c|}
\hline \multirow{2}{*}{\multicolumn{2}{|c|}{ model }} & \multicolumn{2}{|c|}{ Unstandardized coefficient } & Standard coefficient & \multirow{2}{*}{$\mathrm{t}$} & \multirow{2}{*}{ Sig. } & \multirow{2}{*}{$\mathrm{R}^{2}$} & \multirow{2}{*}{ adjusted $\mathrm{R}^{2}$} \\
\hline & & $\mathrm{B}$ & SE & & & & & \\
\hline \multirow{4}{*}{3} & $\mathrm{~b}$ & 1.306 & .271 & & 4.827 & .000 & \multirow{4}{*}{.570} & \multirow{4}{*}{.325} \\
\hline & Work support & .443 & .099 & .389 & 4.464 & .000 & & \\
\hline & Value recognition & .283 & .098 & -.085 & -.848 & .000 & & \\
\hline & Caring interests & .294 & .087 & .308 & 3.381 & .000 & & \\
\hline
\end{tabular}

a. Dependent variable: normative commitment

\section{Conclusions and Inspirations}

The results of regression analysis using spss19.0 are shown in Table 3 below, where work support, value recognition and caring about employees' interests are taken as independent variables and continuance commitment as dependent variable. This study is based on the theory of social exchange, perceived organizational support and career commitment. The theoretical model in this paper is established based on existing literatures and studies. The paper proposed assumptions on perceived organizational support and career commitment with the new generation of employees as the subject for investigation. By using SPSS 19.0 for analysis and verification of assumptions, the paper concluded that:

The perceived organizational support has a significant positive effect on the career commitment of the new generation of employees. Work support has a significant positive effect on affective commitment, continuance commitment and normative commitment. Value recognition has a significant positive effect on affective commitment, continuance commitment and normative commitment. Caring about employees' interests has a significant positive effect on affective commitment, continuance commitment and normative commitment. Among the three dimensions, caring about employees' interests has the greatest impact on affective commitment. The empirical analysis in this study reveals that the three dimensions of perceived organizational support have a positive impact on career commitment of new generation employees. It has the following implications for managers: 1 To create a supportive organizational atmosphere Employees' perception of supportive organizational atmosphere mainly comes from supportive teamwork, supportive organizational environment, and supportive leadership. Organizations can increase communication and interactions with employees through formal mechanism and informal organizational activities, thus raising team awareness and perception and cultivating a stronger sense of belonging. Ensure justice within the organization and raise the citizenship awareness among employees. Transform traditional leadership to a supportive style, thus providing all-round work support for employees.

2 To Recognize the value of employees

The HR department needs to give employees positive feedback, encouragement and recognition of their contributions and care for employees' well-being. Spiritual motivation is especially important for the new generation of employees, a useful tool to make them feel that "they are important" in the organization.

3 To place priority on the interests of employees and always be available to talk

In the formulation of any policy or regulation concerning the very interests of employees, the organization needs to understand the needs and feelings of employees in advance by formal communication, informal communication or even rumor spreading. Before revising or implementing policies or regulations, it is necessary to collect their opinions and ensure the transparency of the whole procedure.

\section{REFERENCES}

[1] Eisenberger R, Huntington R, Hutchison S.et al. Perceived Organizational Support. Journal of Applied Psychology.1986(3):500-507.

[2] Mcmillin R. Customer Satisfaction and Organizational Support for Service Providers[M]. USA: University of Florida, 1997.

[3] Ling Wenzhen, Zhang Zhican, Fang Liluo. A Study on the Commitment of Chinese Staff Organizations [J]. Chinese Social Sciences 2001 (2): 90-102.

[4] Lee PCB Career Goais and Career Management Strategy Among Information Technology Professionals [J] career Development International2002, 7(1) 6-13.

[5] Laurel R Goulet. Parbudyal Singh: Career Commitment: A Reexamination and an Extension, Journal of Vocational Behavior. 2002. 6173-91.

[6] Becker H S. Notes on the Concept of Commitment[J]. American Journal of Sociology, 1960, 66: $32-42$.

[7] Liu Chunfang. Study on the status and influencing factors of occupational commitment of SME employees [J]. Contemporary Economy. 2017,2 (4): 126-128. 
[8] Luo Jiawen. Research on the relationship between professional commitment, organizational support and work engagement of university administrators [D]. South China Normal University, 2008.

[9] Shao Chunyun. A study on the relationship between professional values, organizational support and career success of knowledge workers [D]. Zhejiang Technology and Business University, 2011.

[10] Yi Shizhi. Research on the mechanism of the new generation of highly educated employees 'organizational support and job destruction: a dual intermediary analysis based on career commitment and self-management. Southwestern University of Finance and Economics, 2013

[11] Meyer J P, Allen N J, Smith C A. Commitment to organizations and occupations: extension and test of a three-component model. Journal of Applied Psychology,1993, 78: 538-551.

[12] Lin Xinqi, Su Weilin. Research on Incentive Management of New Generation Employees from the Perspective of Social Exchange Theory [J]. Modern Management Science, 2017 (5): 6-8. 